\title{
Influencing Factors and Exercise Intervention of Cognitive Impairment in Elderly Patients with Chronic Obstructive Pulmonary Disease
}

This article was published in the following Dove Press journal:

Clinical Interventions in Aging

\author{
Ting Wang' \\ Lijuan Mao' \\ Jihong Wang' \\ Peijun $\mathrm{Li}^{1}$ \\ Xiaodan $\mathrm{Liu}^{2,3}$ \\ Weibing Wu (iD) \\ 'Department of Sports Medicine, \\ Shanghai University of Sport, Shanghai \\ 200438, People's Republic of China; \\ ${ }^{2}$ School of Rehabilitation Science, \\ Shanghai University of Traditional \\ Chinese Medicine, Shanghai 201203, \\ People's Republic of China; ${ }^{3}$ Institute of \\ Rehabilitation Medicine, Shanghai \\ Academy of Traditional Chinese \\ Medicine, Shanghai 201203, People's \\ Republic of China
}

\begin{abstract}
Chronic obstructive pulmonary disease (COPD) is a common respiratory condition characterized by airflow limitation in the elderly. Airflow limitation is partially reversible and progressive. COPD not only causes a gradual decline in lung function but also affects the function of other systems throughout the body; it also has adverse effects on the central nervous system that can lead to cognitive impairment, especially in elderly patients. Therefore, understanding the influencing factors of cognitive impairment in elderly patients with COPD and applying early intervention are crucial in improving the quality of life of patients and reducing the burden on their families and society. This article mainly discusses the related factors of cognitive impairment in elderly patients with COPD and expands the possible mechanism of exercise in improving cognitive impairment in patients with COPD to provide a reference for the clinical prevention and treatment of cognitive impairment in elderly patients with COPD.
\end{abstract}

Keywords: chronic obstructive pulmonary disease, elderly people, cognitive function, influencing factors, exercise training

\section{Introduction}

COPD is a common disease of the airways resulting from exposure to noxious particles or gases, characterized by persistent respiratory symptoms and restricted airflow. ${ }^{1}$ By 2020, COPD is projected to become the fifth leading cause of disability and the third leading cause of death worldwide. ${ }^{2}$ Although it has been traditionally considered as a disease primarily affecting the lungs, COPD is often accompanied by many extrapulmonary comorbidities such as heart failure, osteoporosis, muscle atrophy, and cognitive impairment. ${ }^{3}$ With the development of research in recent years, cognitive impairment associated with COPD has attracted considerable attention from scholars. The cognitive impairment not only affects the physical function and health status, ${ }^{4}$ but also aggravates mortality and disability in COPD patients. ${ }^{5,6}$ Studies have found that the mortality rate of elderly COPD patients with cognitive impairment is nearly three times higher than that of elderly patients with cognitive impairment or COPD, ${ }^{7}$ this phenomenon brings substantial economic burden on the patient's family and society.

Exercise training is a core element of pulmonary rehabilitation therapy of COPD. ${ }^{8}$ Studies have confirmed that it can effectively improve the cognitive function of elderly COPD patients and has many neuroprotective effects. ${ }^{9}$ However, current researches on exercise prevention and treatment of cognitive dysfunction in elderly patients with
Correspondence: Weibing Wu

Department of Sports Medicine, Shangha University of Sport, Shanghai 200438

People's Republic of China

Tel +86 21 51253319

Emailwwb75@I26.com

Xiaodan Liu

School of Rehabilitation Science, Shanghai

University of Traditional Chinese

Medicine, Shanghai 201203, People's

Republic of China

Tel +8615800668700

Email hzhp403@I26.com 
COPD is still in its infancy, and significant differences still exist in exercise doses. Thus, the results of different studies cannot be compared, and forming specific movement recommendations is difficult. Therefore, this paper aims to further explore the effect of exercise on cognitive impairment in elderly patients with COPD and its possible mechanism for providing guidance and reference for the exercise rehabilitation of cognitive impairment in elderly patients with COPD.

\section{COPD and Cognitive Impairment}

Cognition is a series of advanced activities in the cerebral cortex, including perception, storage, retrieval, and use of information; such activities enables individual behaviors to adapt to new situations and functions in the environment. ${ }^{10}$ Cognitive function includes many independent areas, such as memory, attention, executive ability, feeling, perception, thinking, learning and judgment. ${ }^{11}$ When one or more of the above mentioned functions are impaired and affect the individual's activities of daily life, the patient has cognitive impairment. This type of impairment ranges from mild cognitive impairment to Alzheimer's disease.

Cognitive impairment is common in patients with COPD. The latest research shows that the prevalence rate of cognitive impairment in stable COPD patients is approximately $56.7 \%$, which is four times higher than that in non-COPD patients. ${ }^{11}$ It affects cognitive functions such as attention, memory, learning, psychomotor speed, visuospatial and motor structures, executive function and language skills in patients with COPD, with memory, attention, and executive function as the most common areas of impairment. ${ }^{12,13}$

Neuroimaging studies have shown that certain brain regions decreased remarkably in patients with COPD, such as the volume of right inferior temporal gyrus, left orbital gyrus, right parahippocampal gyrus, right temporal lobe, bilateral caudate nucleus, bilateral anterior motor cortex, left superior marginal gyrus, and left insular gray matter. ${ }^{14-17}$ The damages of these brain regions are closely related to cognitive impairment in COPD patients. Chen et al pioneered the decomposition of the structure of the cerebral cortex into cortical thickness, surface area (SA) and cortical wrinkles to establish a complete profile of brain injury in COPD patients; and found the SA decreased in the motor, parietal and prefrontal cortex, especially in the dorsomedial prefrontal cortex and Broca's area. ${ }^{18}$ Therefore, cognitive dysfunction in COPD patients may be associated with overall and/or specific brain structural abnormalities.

\section{Influencing Factors of Cognitive Impairment in Elderly Patients with COPD}

Cognitive impairment in elderly patients with COPD is affected by various factors, including disease-specific factors such as hypoxemia, ${ }^{19}$ hypercapnia, ${ }^{20}$ and systemic inflammation, ${ }^{21}$ and lifestyle factors such as diet deficiency, ${ }^{22}$ and lack of physical activity; ${ }^{23,24}$ Other factors, such as aging, ${ }^{25}$ long-term smoking, ${ }^{26,27}$ education, ${ }^{28}$ severity, and course of the disease, ${ }^{29}$ may lead to abnormality in the brain structure and function in COPD patients, resulting in cognitive impairment. Moreover, elderly patients with COPD varying in degrees of synergy are often accompanied by cerebrovascular disease, anxiety and depression, sleep disorders, metabolic syndrome and other complications. ${ }^{30}$ The main influencing factors of the development of elderly patients with COPD cognitive impairment include hypoxemia and hypercapnia, systemic inflammation, cerebrovascular disease, anxiety, and depression.

\section{Hypoxemia and Hypercapnia}

Peripheral airway obstruction and destruction of lung parenchyma reduce gas exchange in the lungs of patients with COPD, resulting in decreased oxygen supply and oxygenation, which finally lead to hypoxemia. ${ }^{31}$ The patients complicated with hypoxemia were in an anoxic state for a long time, and had decreased cerebral perfusion. ${ }^{32}$ When oxygen supply cannot meet the needs of brain metabolism, the microstructure of brain tissue may be damaged, including neuron damage and axonal degeneration. ${ }^{33}$ Research has shown that around $77 \%$ of COPD patients with hypoxemia have cognitive impairment. ${ }^{34}$ Meanwhile, longer duration of COPD could make the brain more vulnerable to hypoxic insults that can result in generation of free radicals, inflammation and neuronal damage. ${ }^{35}$ Furthermore, patients with COPD tend to have hyper carbonic acidemia in the later stage of disease course due to the retention of carbon dioxide in the body and the increase of carbon dioxide concentration in the blood. ${ }^{36}$ Hypercapnia can induce the production of oxygen-free radicals and block the synthesis of neurotransmitters such as acetylcholine, and result in overall neuronal damage. ${ }^{11}$ Finally, Patients also show symptoms such as prolonged reaction time, slow information processing speed, delayed memory, and attention deficit. ${ }^{37}$ 


\section{Systemic Inflammation}

The long-term pulmonary inflammatory response caused by COPD will break the balance of injury repair mechanism of the immune system, and the overflow of inflammatory mediators in the airway into the blood circulation leads to a systemic inflammatory response, and results in the damage to the structure and function of extrapulmonary organs. ${ }^{38}$ Various immune cells and inflammatory mediators, including neutrophils, macrophages, interleukin-6 (IL-6), IL-8, tumor necrosis factor- $\alpha$ (TNF- $\alpha$ ) and C-reactive protein (CRP), are involved in the occurrence and development of COPD. ${ }^{39}$ The increase in IL- 6 and CRP levels is related to the decrease in overall cognitive and executive functions. ${ }^{40}$ This increase can cause secondary vascular cognitive impairment by participating in the occurrence of cardiovascular diseases such as atherosclerosis. $^{21}$ Long-term inflammatory stimulation acts on the vascular endothelium, and results in vascular endothelial impairment, which leads to the destruction of blood-brain barrier function and structural changes in cerebral vessels of patients with COPD, and subsequently lead to the impairment of attention and memory of patients. ${ }^{41}$ Furthermore, to improve the inflammation, patients with COPD often use bronchodilators such as long-acting $\beta$-adrenoceptor agonist and long-acting muscarinic antagonist, which can also inhibit the central nervous system and cause damage to the attention function of COPD patients. ${ }^{10}$

\section{Cerebrovascular Disease}

A study found that elderly patients with COPD have a high risk of cerebral microhemorrhage. ${ }^{42}$ Cerebral microhemorrhage is an important imaging marker of Cerebral small vessel disease (CSVD) recently. CSVD is the microvascular lesion of white and gray matter, it is a group of pathological processes with a variety of etiology and pathogenesis, ${ }^{43}$ that mainly involves small blood vessels such as cerebral arteries, veins and capillaries. Cerebral microhemorrhage can cause damage to the structural network of the brain, ${ }^{44}$ and increase the risk of cognitive impairment. ${ }^{45}$ Meanwhile, it is also associated with impaired executive function, attention and processing speed, and overall cognitive ability. ${ }^{46}$ In addition, vascular inflammation can accelerate endothelial impairment and atherosclerosis. Arteriosclerosis can reduce vascular compliance, increase pulse pressure difference, and deliver increased blood flow to fine cerebral microvessels; Thus, it causes microvascular brain damage and atrophy, ${ }^{47}$ and ultimately decreases the cognitive ability of patients with COPD in terms of speed and executive function. ${ }^{48}$

\section{Anxiety and Depression}

The respiratory function of elderly patients with COPD that has been seriously damaged for a long time, Meanwhile, a variety of factors including physical activity limitation, social activity impairment, physical deterioration, and social and economic factors' interaction, likely result in anxiety, depression and other negative emotions of COPD patients. ${ }^{49}$ Studies have shown that more than one-third of COPD patients have comorbid symptoms of depression and anxiety. ${ }^{50}$ Previous studies have also confirmed that anxiety and depression are independent risk factors and precursor symptoms of cognitive impairment, ${ }^{51}$ that can also cause morphological and functional changes in the medial amygdala, prefrontal cortex and hippocampus. ${ }^{52}$ Fritzsche et al also found that COPD patients with depression demonstrated clear cognitive impairment. ${ }^{53}$ Other scholars have also found that the elderly with depression and anxiety showed poor speech fluency ${ }^{54}$ likely due to long-term depression in elderly patients with COPD. Depression will significantly reduce communication with the outside world, and patients with social communication dysfunction will affect their cognitive function.

\section{Effects of Exercise on Cognitive Impairment in Elderly Patients with COPD}

Exercise training is an essential part of pulmonary rehabilitation in patients with COPD. ${ }^{55}$ Studies have shown that regular exercise can enhance the function of the central nervous system and reduce the risk of cognitive impairment. ${ }^{56-58}$ Emery et al found that exercise training for $20 \mathrm{~min}$ can improve the performance of elderly COPD patients in language fluency tests. ${ }^{59}$ Kozora et al found that after 3 weeks of exercise training, cognitive functions, such as visual attention, verbal memory and visual-spatial function in elderly patients with COPD improved. ${ }^{60}$ Aquino et al also found that aerobic exercise combined resistance training for 4 weeks, twice a day for $30 \mathrm{~min}$, can significantly improve the performance of cognitive areas including fluid intelligence, long-term memory, attention and reasoning in elderly patients with COPD. ${ }^{61}$ Furthermore, compared with elderly COPD patients who 


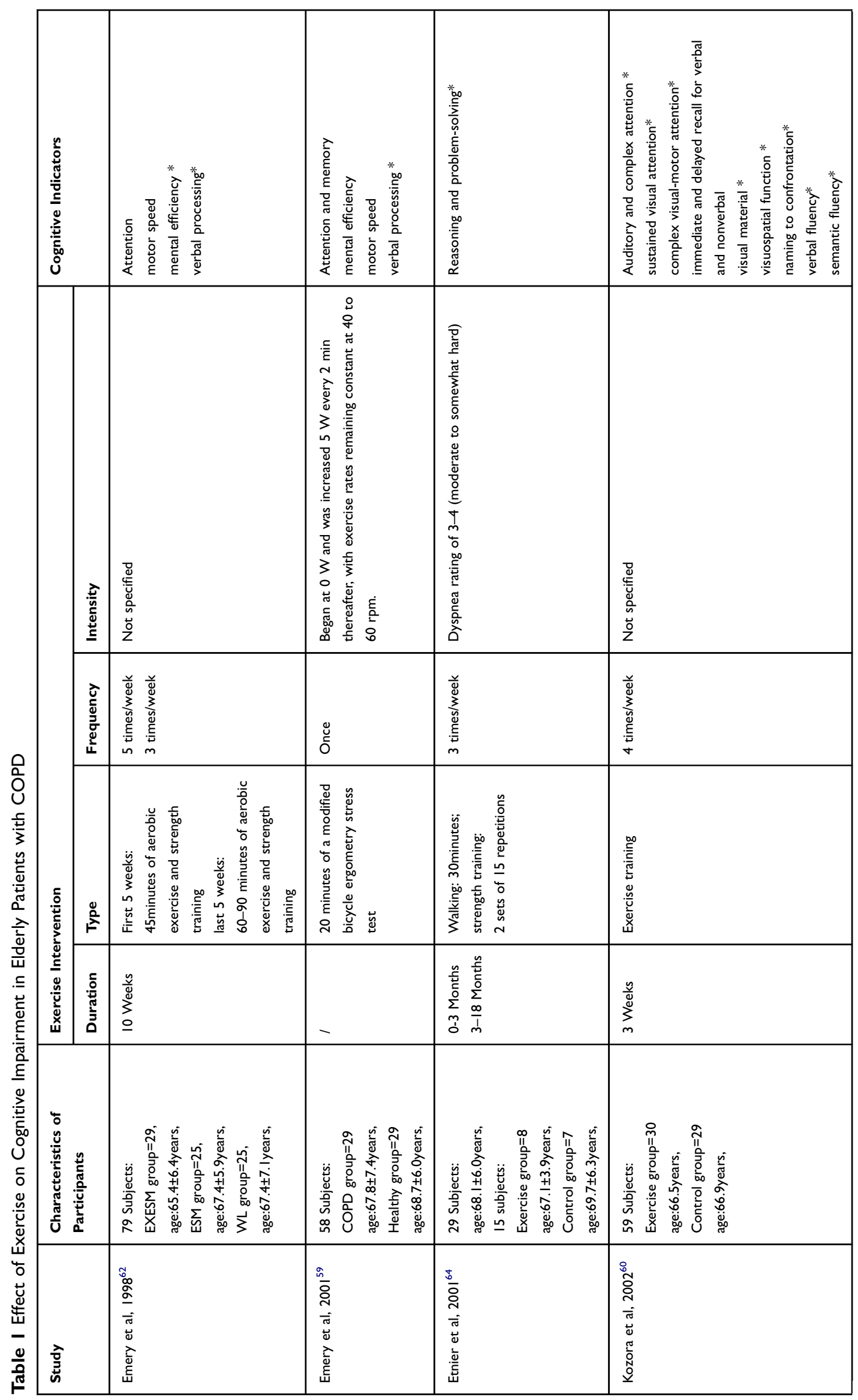




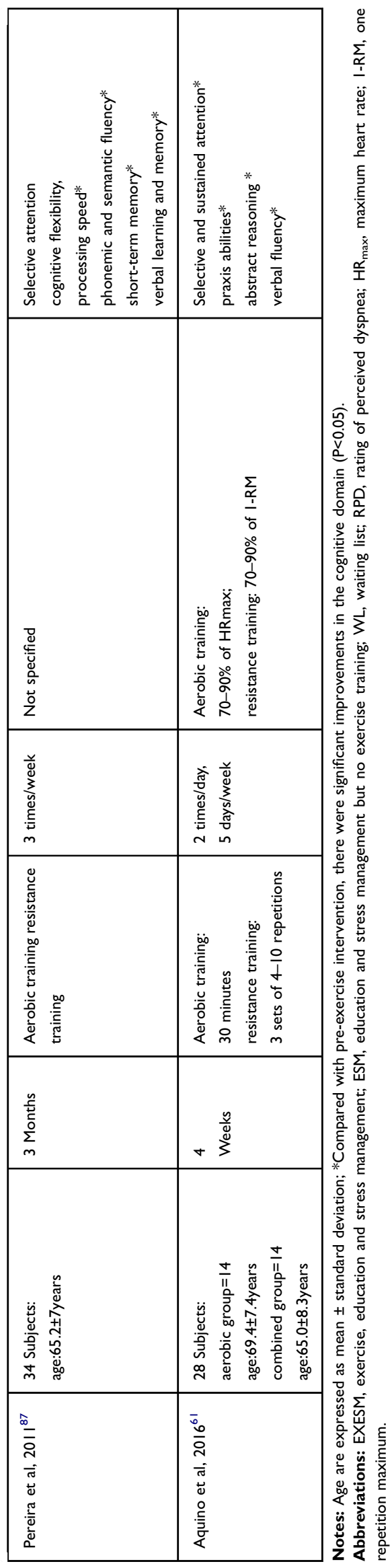

did not receive exercise training, the language fluency of patients who underwent exercise training significantly improved after 10 weeks of training. ${ }^{62}$ Emery et al followed patients for 1 year after completing a 10 -week exercise program and found that $39 \%$ of patients with continuous exercise maintained cognitive improvement, while those who stopped exercising showed cognitive decline. ${ }^{63}$ Therefore, long-term and regular exercise training can reduce the incidence of cognitive impairment in elderly patients with COPD.

The exercise intervention programs for elderly COPD patients with cognitive impairment in some studies are described in the following sections (Table 1).

\section{Possible Mechanism of Exercise on the Improvement Cognitive Impairment of Elderly Patients with COPD}

As the main metabolic organ of oxygen, the brain has a large number of easily oxidized unsaturated fat, high levels of reactive oxygen species, therefore, the brain is particularly susceptible to oxidative damage. ${ }^{65}$ Given the decrease in partial pressure of blood oxygen and brain hypoxia in patients with COPD, oxidative stress occurs easily, and results in the production of lipid peroxidation, which aggravates the damage in brain tissue and leads to the degeneration of brain neurons and cognitive dysfunction. ${ }^{66}$ Studies have found that exercise can improve oxidative stress in patients with COPD. Lu et al determined that exercise can reduce the production of peroxynitrite, lipid peroxidation, and oxidative DNA damage. ${ }^{65}$ Kwon et al also found that exercise increases the antioxidant defense response and protects against sleep deprivation and chronic cerebral lipid peroxidation, which reduced oxidative damage and improved cognitive function. ${ }^{67}$ Therefore, exercise training play an positive role in affecting the anti-oxidative stress for the inhibition of the oxidative damage in lipids, proteins and nucleic acids, and also the contribution of neuroprotection and cognitive improvement.

Exercise has been increasingly recognized as a potential intervention for reducing chronic inflammation. ${ }^{68,69}$ Studies have shown that old people with exercise are less prone to systemic inflammation than older people without exercise. ${ }^{70}$ Nascimento et al conducted a 16-week multi-mode physical exercise program for the elderly with cognitive impairment and found that exercise training can effectively reduce the 
TNF- $\alpha$ level and improve their cognitive ability. ${ }^{71}$ As a critical anti-inflammatory cytokine, IL-10 inhibits systemic inflammation and plays a vital role in inhibiting the production of TNF- $\alpha .^{72}$ Chupel et al found that a 28 -week program of strength training can improve the overall cognitive performance of older women with cognitive impairment by increasing the IL-10 levels and reducing the total white blood cell and lymphocyte counts. ${ }^{73}$ Chupel et al also determined that 14 weeks of exercise training reduced the production of pro-inflammatory cytokines in older women, improved their chronic inflammation, and maintained the integrity of their blood-brain barrier; as a result, cognitive impairment slowed down. ${ }^{74}$

The integrity of brain function is dependent on the continuous and steady blood supply of the cerebral circulation, especially the cerebral microvascular system. Compared with healthy subjects, the cerebral perfusion of the frontal and parietal lobes was significantly decreased in patients with COPD. ${ }^{75}$ Exercise can up-regulate angiogenic factors such as vascular endothelial growth factor and insulin-like growth factor-1, and thus promote cerebral perfusion and improve the cognitive function. ${ }^{76}$ Exercise can also enhance the efficiency of oxygen transport and utilization in the brain environment, ${ }^{77}$ promote angiogenesis in parts of the brain and activate additional brain regions that increase metabolic activity in the brain of COPD patients. Kramer et al found that exercise increased the utilization of oxygen and improved the performance of the elderly in functional tests. ${ }^{78}$ In addition, increasing the flow of oxygen to the brain after exercise boosts the metabolism of neurotransmitters (norepinephrine [NE], acetylcholine, and dopamine [DA]) and factors that stimulate angiogenesis and synaptic development. ${ }^{79}$ The process of neurogenesis, consequently promotes the production of neurotransmitters and their receptors to increase the brain's plasticity and repairability. ${ }^{80}$

Exercise can enhance the metabolism of monoamine neurotransmitters, such as DA, 5-hydroxytryptamine, and $\mathrm{NE}$, to improve the state of depression and the ability of information processing. ${ }^{81}$ Lin et al found that the anxiety and depression of COPD patients improved significantly after 3 months of walking training. ${ }^{82}$ Tselebis et al evaluated COPD patients with the Beck depression scale and found that 3 months of aerobic exercise significantly reduced the depression and anxiety scores. ${ }^{83}$ Lavoie et al also found that anxiety and depression reduced with increases in either physical activity or exercise capacity, and cognitive function improved with increased exercise capacity in COPD patients. ${ }^{84}$ Moreover, exercise

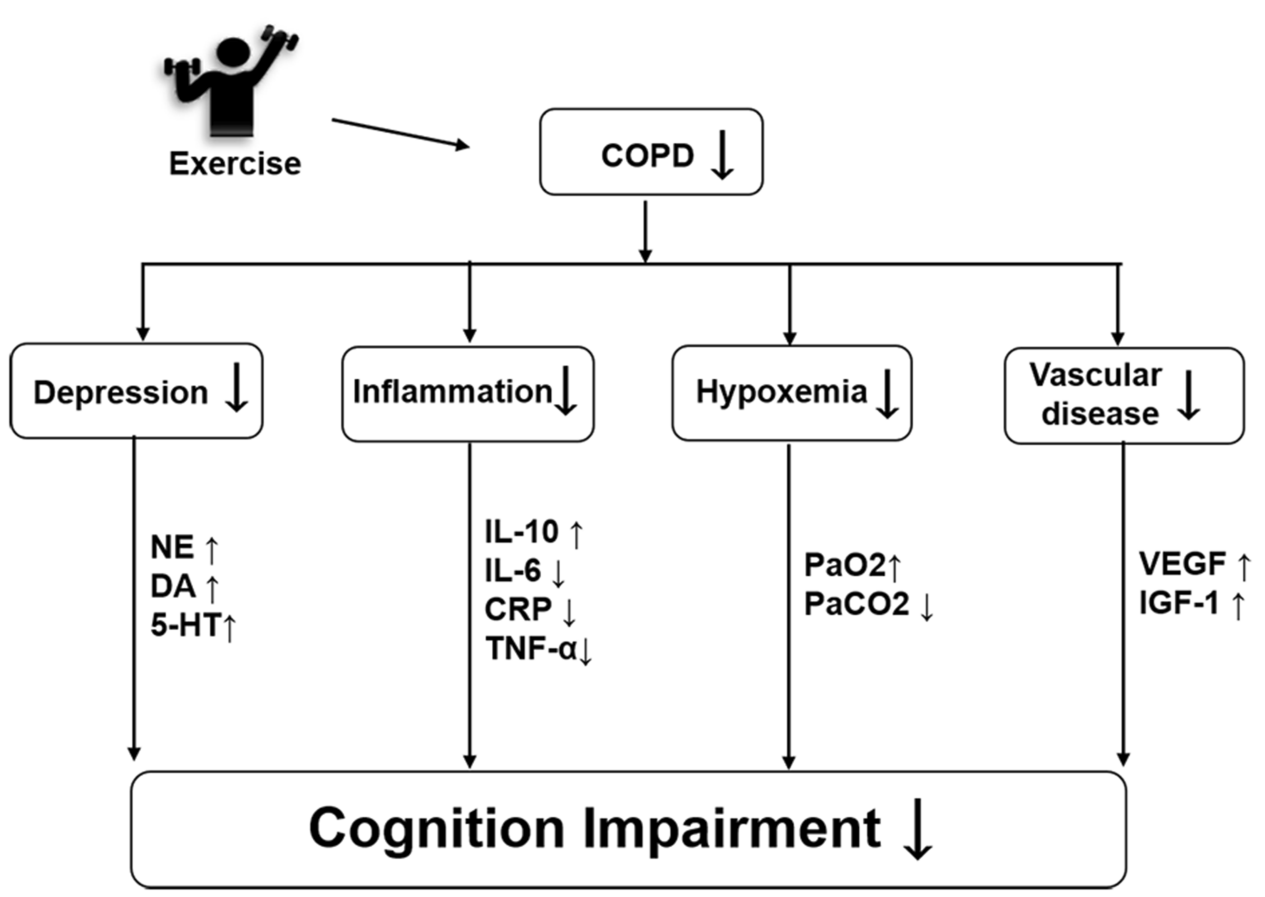

Figure I The possible mechanism of exercise improving cognitive impairment in the elderly with COPD.

Abbreviations: NE, norepinephrine; DA, dopamine; 5-HT, 5-hydroxytryptamine; IL-10, interleukin-I0; IL-6, interleukin-6; CRP, C-reactive protein; TNF- $\alpha$, tumor necrosis factor- $\alpha$; $\mathrm{PaO} 2$, partial arterial blood oxygen pressure; $\mathrm{PaCO} 2$, partial arterial carbon dioxide pressure; VEGF, vascular endothelial growth factor; IGF-I, insulin-like growth factor-I. 
can change the structure of the central nervous system, specifically by changing the plasticity of the cerebral cortex, slowing the atrophy of gray and white matter, changing the structure and function of the frontal, parietal and temporal lobes of the brain, ${ }^{85}$ and increasing the volume of hippocampus, ${ }^{86}$ to maintain the stability in cognitive function of patients with COPD. Therefore, increasing exercise capacity can improve psychological and cognitive outcomes in patients with COPD. In summary, exercise can improve cognitive performance in elderly patients with COPD through multiple pathways, such as improving oxidative stress, systemic inflammation, cerebrovascular function, and anxiety and depression. Meanwhile, the mechanism of the cognitive improvement caused by exercise intervention needs to be further studied and combined with the mechanism of the occurrence and development of cognitive impairment to explain its neuropathological process fundamentally.

Figure 1 show the possible mechanism of exercise improving cognitive impairment in the elderly with COPD.

\section{Conclusion}

The Cognitive dysfunction is a common complication of COPD, which is related to hypoxemia, hypercapnia, systemic inflammation, anxiety and depression. These factors lead to abnormal brain structure and function, and finally cause the manifestation of the symptom of cognitive function impairment in the elderly COPD patients. As most of the patients with COPD are old and have long suffered with the disease, cognitive impairment will not only affect the quality of life of the patients but also bring significant challenges to the medical and health system. Exercise training, which is a core element of COPD lung rehabilitation, can reduce the cognitive impairment of COPD patients through many ways, which are important in improving the quality of life of elderly COPD patients.

\section{Acknowledgments}

The authors would like to thank Mr Jian Li, Mr Zhaoyu Yang, Ms Hongxia Duan and Ms Yahui Yang for their Information gathering and assistance with this study. This work was supported by the National Natural Science Foundation of China (No 81902307).

\section{Disclosure}

The authors report no conflicts of interest in this work.

\section{References}

1. Singh D, Agusti A, Anzueto A, et al. Global strategy for the diagnosis, management, and prevention of chronic obstructive lung disease: the GOLD science committee report 2019. Eur Respir J. 2019;53(5):1900164. doi:10.1183/13993003.00164-2019

2. Jemal A, Ward E, Hao Y, Thun M. Trends in the leading causes of death in the United States, 1970-2002. JAMA. 2005;294 (10):1255-1259. doi:10.1001/jama.294.10.1255

3. Cavailles A, Brinchault-Rabin G, Dixmier A, et al. Comorbidities of COPD. Eur Respir Rev. 2013;22(130):454-475. doi:10.1183/0905 9180.00008612

4. O'Conor R, Muellers K, Arvanitis M, et al. Effects of health literacy and cognitive abilities on COPD self-management behaviors: a prospective cohort study. Respir Med. 2019;160:105630. doi:10. 1016/j.rmed.2019.02.006

5. Campbell NL, Boustani MA, Skopelja EN, Gao S, Unverzagt FW, Murray MD. Medication adherence in older adults with cognitive impairment: a systematic evidence-based review. Am J Geriatr Pharmacother. 2012;10(3):165-177. doi:10.1016/j.amjopharm.2012. 04.004

6. Perneczky R, Pohl C, Sorg C, et al. Impairment of activities of daily living requiring memory or complex reasoning as part of the MCI syndrome. Int J Geriatr Psychiatry. 2006;21(2):158-162. doi:10. 1002/gps. 1444

7. Chang SS, Chen S, McAvay GJ, Tinetti ME. Effect of coexisting chronic obstructive pulmonary disease and cognitive impairment on health outcomes in older adults. J Am Geriatr Soc. 2012;60 (10):1839-1846. doi:10.1111/j.1532-5415.2012.04171.x

8. Spruit MA, Singh SJ, Garvey C, et al. An official American Thoracic Society/European Respiratory Society statement: key concepts and advances in pulmonary rehabilitation. Am J Respir Crit Care Med. 2013;188(8):e13-e64. doi:10.1164/rccm.201309-1634ST

9. Desveaux L, Harrison SL, Gagnon JF, Goldstein RS, Brooks D, Pepin V. Effects of exercise training on cognition in chronic obstructive pulmonary disease: a systematic review. Respir Med. 2018;139:110-116. doi:10.1016/j.rmed.2018.05.006

10. van Beers M, Janssen DJA, Gosker HR, Schols A. Cognitive impairment in chronic obstructive pulmonary disease: disease burden, determinants and possible future interventions. Expert Rev Respir Med. 2018;139:1-14.

11. Cleutjens FA, Janssen DJ, Ponds RW, Dijkstra JB, Wouters EF. COgnitive-pulmonary disease. Biomed Res Int. 2014;2014 (2014):697825. doi:10.1155/2014/697825

12. Andreou G, Vlachos F, Makanikas K. Effects of chronic obstructive pulmonary disease and obstructive sleep apnea on cognitive functions: evidence for a common nature. Sleep Disord. 2014;2014:768210. doi:10.1155/2014/768210

13. Bajaj M-PK, Burrage DR, Tappouni A, Dodd JW, Jones PW, Baker EH. COPD patients hospitalized with exacerbations have greater cognitive impairment than patients hospitalized with decompensated heart failure. Clin Interv Aging. 2018;14:1-8. doi:10.2147/ CIA.S185981

14. Borson S, Scanlan J, Friedman S, et al. Modeling the impact of COPD on the brain. Int J Chron Obstruct Pulmon Dis. 2008;3 (3):429-434. doi:10.2147/COPD.S2066

15. Dodd JW, Chung AW, van den Broek MD, Barrick TR, Charlton RA, Jones PW. Brain structure and function in chronic obstructive pulmonary disease: a multimodal cranial magnetic resonance imaging study. Am J Respir Crit Care Med. 2012;186(3):240-245. doi:10.1 164/rccm.201202-0355OC

16. Ryu CW, Jahng GH, Choi CW, et al. Microstructural change of the brain in chronic obstructive pulmonary disease: a voxel-based investigation by MRI. COPD. 2013;10(3):357-366. doi:10.3109/154125 55.2012 .752808 
17. Spilling CA, Jones PW, Dodd JW, Barrick TR. White matter lesions characterise brain involvement in moderate to severe chronic obstructive pulmonary disease, but cerebral atrophy does not. BMC Pulm Med. 2017;17(1):92. doi:10.1186/s12890-017-0435-1

18. Chen J, Lin IT, Zhang H, et al. Reduced cortical thickness, surface area in patients with chronic obstructive pulmonary disease: a surface-based morphometry and neuropsychological study. Brain Imaging Behav. 2016;10(2):464-476. doi:10.1007/s11682-015-9403-7

19. Wen XH, Li Y, Han D, Sun L, Ren PX, Ren D. The relationship between cognitive function and arterial partial pressure $\mathrm{O} 2$ in patients with COPD: a meta-analysis. Medicine (Baltimore). 2018;97(4): e9599. doi:10.1097/MD.0000000000009599

20. Zheng GQ, Wang Y, Wang XT. Chronic hypoxia-hypercapnia influences cognitive function: a possible new model of cognitive dysfunction in chronic obstructive pulmonary disease. Med Hypotheses. 2008;71(1):111-113. doi:10.1016/j.mehy.2008.01.025

21. Warnberg J, Gomez-Martinez S, Romeo J, Diaz LE, Marcos A. Nutrition, inflammation, and cognitive function. Ann N Y Acad Sci. 2009;1153:164-175. doi:10.1111/j.1749-6632.2008.03985.x

22. Hayden KM, Beavers DP, Steck SE, et al. The association between an inflammatory diet and global cognitive function and incident dementia in older women: the Women's Health Initiative Memory Study. Alzheimers Dement. 2017;13(11):1187-1196. doi:10.1016/j.jalz.2017.04.004

23. Sabia S, Dugravot A, Dartigues JF, et al. Physical activity, cognitive decline, and risk of dementia: 28 year follow-up of Whitehall II cohort study. BMJ. 2017;357:j2709. doi:10.1136/bmj.j2709

24. Brasure M, Desai P, Davila H, et al. Physical activity interventions in preventing cognitive decline and alzheimer-type dementia: a systematic review. Ann Intern Med. 2018;168(1):30-38. doi:10.7326/M17-1528

25. Barnes JN. Exercise, cognitive function, and aging. Adv Physiol Educ. 2015;39(2):55-62. doi:10.1152/advan.00101.2014

26. Anstey KJ, von Sanden C, Salim A, O'Kearney R. Smoking as a risk factor for dementia and cognitive decline: a meta-analysis of prospective studies. Am J Epidemiol. 2007;166(4):367-378. doi:10.1093/ aje/kwm116

27. Evans DA, Beckett LA, Albert MS, et al. Level of education and change in cognitive function in a community population of older persons. Ann Epidemiol. 1993;3(1):71-77. doi:10.1016/10472797(93)90012-S

28. Park SK. Trajectories of change in cognitive function in people with chronic obstructive pulmonary disease. J Clin Nurs. 2018;27(7-8):1529-1542. doi:10.1111/jocn.14285

29. Zayats YV, Kotel'nikov VN, Gel'tser BI, Plekhova NG. Behavioral and cognitive reactions of rats with experimental chronic obstructive lung diseases of different degree. Bull Exp Biol Med. 2019;166 (5):602-605. doi:10.1007/s10517-019-04400-8

30. Cebron Lipovec N, Beijers RJ, van den Borst B, Doehner W, Lainscak M, Schols AM. The prevalence of metabolic syndrome in chronic obstructive pulmonary disease: a systematic review. COPD. 2016;13(3):399-406. doi:10.3109/15412555.2016.1140732

31. Andrianopoulos V, Gloeckl R, Vogiatzis I, Kenn K. Cognitive impairment in COPD: should cognitive evaluation be part of respiratory assessment? Breathe (Sheff). 2017;13(1):e1-e9. doi:10.1183/ 20734735.001417

32. Esser RW, Stoeckel MC, Kirsten A, et al. Structural brain changes in patients with COPD. Chest. 2016;149(2):426-434. doi:10.1378/ chest.15-0027

33. Watz H, Waschki B, Kirsten A, et al. The metabolic syndrome in patients with chronic bronchitis and COPD: frequency and associated consequences for systemic inflammation and physical inactivity. Chest. 2009;136(4):1039-1046. doi:10.1378/chest.09-0393

34. Savage CC, Dixey PHA, Pennington C, Dodd JW. Visual rating assessment of cerebral atrophy and its relationship with cognitive function in chronic obstructive pulmonary disease. BMJ Open Respir Res. 2018;5(1):e000310. doi:10.1136/bmjresp-2018-000310
35. Tudorache E, Fildan AP, Frandes M, Dantes E, Tofolean DE. Aging and extrapulmonary effects of chronic obstructive pulmonary disease. Clin Interv Aging. 2017;12:1281-1287. doi:10.2147/CIA.S145002

36. Abdo WF, Heunks LM. Oxygen-induced hypercapnia in COPD: myths and facts. Crit Care. 2012;16(5):323. doi:10.1186/cc11475

37. Klein M, Gauggel S, Sachs G, Pohl W. Impact of chronic obstructive pulmonary disease (COPD) on attention functions. Respir Med. 2010;104(1):52-60. doi:10.1016/j.rmed.2009.08.008

38. Barnes PJ, Celli BR. Systemic manifestations and comorbidities of COPD. Eur Respir J. 2009;33(5):1165-1185. doi:10.1183/0903 1936.00128008

39. Sartori AC, Vance DE, Slater LZ, Crowe M. The impact of inflammation on cognitive function in older adults: implications for healthcare practice and research. J Neurosci Nurs. 2012;44(4):206-217. doi:10.1097/JNN.0b013e3182527690

40. Schram MT, Euser SM, de Craen AJM, et al. Systemic markers of inflammation and cognitive decline in old age. $J$ Am Geriatr Soc. 2007;55(5):708-716. doi:10.1111/j.1532-5415.2007.01159.x

41. Kirkil G, Tug T, Ozel E, Bulut S, Tekatas A, Muz MH. The evaluation of cognitive functions with P300 test for chronic obstructive pulmonary disease patients in attack and stable period. Clin Neurol Neurosurg. 2007;109(7):553-560. doi:10.1016/j.clineuro.2007.03.013

42. Lahousse L, Vernooij MW, Darweesh SKL, et al. Chronic obstructive pulmonary disease and cerebral microbleeds. The Rotterdam Study. Am J Respir Crit Care Med. 2013;188(7):783-788. doi:10.1164/ rccm.201303-0455OC

43. Cai Z, Wang C, He W, et al. Cerebral small vessel disease and alzheimer's disease. Clin Interv Aging. 2015;10:1695-1704. doi:10.2147/CIA.S90871

44. Heringa SM, Reijmer YD, Leemans A, Koek HL, Kappelle LJ, Biessels GJ. Multiple microbleeds are related to cerebral network disruptions in patients with early alzheimer's disease. Nat Rev Immunol. 2014;38(1):211-221. doi:10.3233/JAD-130542

45. Wu R, Feng C, Zhao Y, Jin AP, Fang M, Liu X. A meta-analysis of association between cerebral microbleeds and cognitive impairment. Med Sci Monit. 2014;20:2189-2198. doi:10.12659/MSM.891004

46. Yates PA, Villemagne VL, Ellis KA, Desmond PM, Masters CL, Rowe CC. Cerebral microbleeds: a review of clinical, genetic, and neuroimaging associations. Front Neurol. 2014;4:205. doi:10.3389/ fneur.2013.00205

47. Zeki Al Hazzouri A, Yaffe K, de la Torre JC. Arterial stiffness and cognitive function in the elderly. Nat Rev Immunol. 2014;42(Supp1 s4):S503-S514. doi:10.3233/JAD-141563

48. Pantoni L. Cerebral small vessel disease: from pathogenesis and clinical characteristics to therapeutic challenges. Lancet Neurol. 2010;9(7):689-701. doi:10.1016/S1474-4422(10)70104-6

49. Lecheler L, Richter M, Franzen DP, et al. The frequent and underrecognised co-occurrence of acute exacerbated COPD and depression warrants screening: a systematic review. Eur Respir Rev. 2017;26 (144):170026. doi:10.1183/16000617.0026-2017

50. Panagioti M, Scott C, Blakemore A, Coventry PA. Overview of the prevalence, impact, and management of depression and anxiety in chronic obstructive pulmonary disease. Int J Chron Obstruct Pulmon Dis. 2014;9:1289-1306. doi:10.2147/COPD.S72073

51. Hasselbalch BJ, Knorr U, Hasselbalch SG, Gade A, Kessing LV. The cumulative load of depressive illness is associated with cognitive function in the remitted state of unipolar depressive disorder. Eur Psychiatry. 2013;28(6):349-355. doi:10.1016/j.eurpsy.2012.03.004

52. van Tol MJ, van der Wee NJ, van den Heuvel OA, et al. Regional brain volume in depression and anxiety disorders. Arch Gen Psychiatry. 2010;67(10):1002-1011. doi:10.1001/archgenpsychiatry. 2010.121

53. Fritzsche A, Watz H, Magnussen H, Tuinmann G, Lowe B, von Leupoldt A. Cognitive biases in patients with chronic obstructive pulmonary disease and depression-a pilot study. $\mathrm{Br} J$ Health Psychol. 2013;18(4):827-843. doi:10.1111/bjhp.12025 
54. Johnco C, Wuthrich VM, Rapee RM. The impact of late-life anxiety and depression on cognitive flexibility and cognitive restructuring skill acquisition. Depress Anxiety. 2015;32(10):754-762. doi:10.1002/da.22375

55. Maltais F, Decramer M, Casaburi R, et al. An official American Thoracic Society/European Respiratory Society statement: update on limb muscle dysfunction in chronic obstructive pulmonary disease. Am J Respir Crit Care Med. 2014;189(9):e15-e62. doi:10.1164/rccm.201402-0373ST

56. Ruscheweyh R, Willemer C, Kruger K, et al. Physical activity and memory functions: an interventional study. Neurobiol Aging. 2011;32 (7):1304-1319. doi:10.1016/j.neurobiolaging.2009.08.001

57. Gomez-Pinilla F, Hillman C. The influence of exercise on cognitive abilities. Compr Physiol. 2013;3(1):403-428. doi:10.1002/cphy. c110063

58. Rockwood K, Middleton L. Physical activity and the maintenance of cognitive function. Alzheimers Dement. 2007;3(2 Suppl):S38-S44. doi:10.1016/j.jalz.2007.01.003

59. Emery CF, Honn VJ, Frid DJ, Lebowitz KR, Diaz PT. Acute effects of exercise on cognition in patients with chronic obstructive pulmonary disease. Am J Respir Crit Care Med. 2001;164(9):1624-1627. doi:10.1164/ajrccm.164.9.2104137

60. Kozora E, Tran ZV, Make B. Neurobehavioral improvement after brief rehabilitation in patients with chronic obstructive pulmonary disease. J Cardiopulm Rehabil. 2002;22(6):426-430. doi:10.1097/ 00008483-200211000-00008

61. Aquino G, Iuliano E, Di Cagno A, et al. Effects of combined training vs aerobic training on cognitive functions in COPD: a randomized controlled trial. Int J Chron Obstruct Pulmon Dis. 2016;11:711-718. doi:10.2147/COPD.S96663

62. Emery CF, Schein RL, Hauck ER, MacIntyre NR. Psychological and cognitive outcomes of a randomized trial of exercise among patients with chronic obstructive pulmonary disease. Health Psychol. 1998;17 (3):232-240. doi:10.1037/0278-6133.17.3.232

63. Emery CF, Shermer RL, Hauck ER, Hsiao ET, MacIntyre NR. Cognitive and psychological outcomes of exercise in a 1-year follow-up study of patients with chronic obstructive pulmonary disease. Health Psychol. 2003;22(6):598-604. doi:10.1037/02786133.22.6.598

64. Etnier JL, Berry M. Fluid intelligence in an older COPD sample after short- or long-term exercise. Med Sci Sports Exerc. 2001;33 (10):1620-1628. doi:10.1097/00005768-200110000-00002

65. Lu Y, Dong Y, Tucker D, et al. Treadmill exercise exerts neuroprotection and regulates microglial polarization and oxidative stress in a streptozotocin-induced rat model of sporadic alzheimer's disease. Nat Rev Immunol. 2017;56(4):1469-1484. doi:10.3233/JAD-160869

66. Cleutjens F, Ponds R, Spruit MA, et al. The relationship between cerebral small vessel disease, hippocampal volume and cognitive functioning in patients with COPD: an MRI Study. Front Aging Neurosci. 2017;9:88. doi:10.3389/fnagi.2017.00088

67. Kwon DH, Kim BS, Chang H, Kim YI, Jo SA, Leem YH. Exercise ameliorates cognition impairment due to restraint stress-induced oxidative insult and reduced BDNF level. Biochem Biophys Res Commun. 2013;434(2):245-251. doi:10.1016/j.bbrc.2013.02.111

68. Ertek S, Cicero A. Impact of physical activity on inflammation: effects on cardiovascular disease risk and other inflammatory conditions. Arch Med Sci. 2012;8(5):794-804. doi:10.5114/ aoms.2012.31614

69. Mathur N, Pedersen BK. Exercise as a mean to control low-grade systemic inflammation. Mediators Inflamm. 2008;2008:109502. doi:10.1155/2008/109502

70. Beavers KM, Brinkley TE, Nicklas BJ. Effect of exercise training on chronic inflammation. Clin Chim Acta. 2010;411(11-12):785-793. doi:10.1016/j.cca.2010.02.069
71. Nascimento CM, Pereira JR, de Andrade LP, et al. Physical exercise in MCI elderly promotes reduction of pro-inflammatory cytokines and improvements on cognition and BDNF peripheral levels. Curr Alzheimer Res. 2014;11(8):799-805. doi:10.2174/1567205011081409 10122849

72. Saraiva M, O'Garra A. The regulation of IL-10 production by immune cells. Nat Rev Immunol. 2010;10(3):170-181. doi:10.1038/ nri2711

73. Chupel MU, Direito F, Furtado GE, et al. Strength training decreases inflammation and increases cognition and physical fitness in older women with cognitive impairment. Front Physiol. 2017;8:377. doi:10.3389/fphys.2017.00377

74. Chupel MU, Minuzzi LG, Furtado G, et al. Exercise and taurine in inflammation, cognition, and peripheral markers of blood-brain barrier integrity in older women. Appl Physiol Nutr Metab. 2018;43 (7):733-741. doi:10.1139/apnm-2017-0775

75. Ortapamuk H, Naldoken S. Brain perfusion abnormalities in chronic obstructive pulmonary disease: comparison with cognitive impairment. Ann Nucl Med. 2006;20(2):99-106. doi:10.1007/ BF02985621

76. Alkadhi KA. Exercise as a positive modulator of brain function. $\mathrm{Mol}$ Neurobiol. 2018;55(4):3112-3130.

77. Tyndall AV, Davenport MH, Wilson BJ, et al. The brain-in-motion study: effect of a 6-month aerobic exercise intervention on cerebrovascular regulation and cognitive function in older adults. $B M C$ Geriatr. 2013;13(1):21. doi:10.1186/1471-2318-13-21

78. Kramer AF, Hahn S, Cohen NJ, et al. Ageing, fitness and neurocognitive function. Nature. 1999;400(6743):418-419. doi:10.1038/22682

79. Maass A, Duzel S, Brigadski T, et al. Relationships of peripheral IGF-1, VEGF and BDNF levels to exercise-related changes in memory, hippocampal perfusion and volumes in older adults. Neuroimage. 2016;131:142-154. doi:10.1016/j.neuroimage.2015.10.084

80. Deslandes A, Moraes H, Ferreira C, et al. Exercise and mental health: many reasons to move. Neuropsychobiology. 2009;59(4):191-198. doi: $10.1159 / 000223730$

81. Archer T, Josefsson T, Lindwall M. Effects of physical exercise on depressive symptoms and biomarkers in depression. CNS Neurol Disord Drug Targets. 2014;13(10):1640-1653. doi:10.2174/ 1871527313666141130203245

82. Lin F-L, Yeh M-L, Lai Y-H, Lin K-C, Yu C-J, Chang J-S. Two-month breathing-based walking improves anxiety, depression, dyspnoea and quality of life in chronic obstructive pulmonary disease: a randomised controlled study. J Clin Nurs. 2019;28(19-20):3632-3640. doi:10.1111/jocn. 14960

83. Tselebis A, Bratis D, Pachi A, et al. A pulmonary rehabilitation program reduces levels of anxiety and depression in COPD patients. Multidiscip Respir Med. 2013;8(1):41. doi:10.1186/20496958-8-41

84. Lavoie KL, Sedeno M, Hamilton A, et al. Behavioural interventions targeting physical activity improve psychocognitive outcomes in COPD. ERJ Open Res. 2019;5(4):00013-02019. doi:10.1183/ 23120541.00013-2019

85. Gomes-Osman J, Cabral DF, Hinchman C, Jannati A, Morris TP, Pascual-Leone A. The effects of exercise on cognitive function and brain plasticity - a feasibility trial. Restor Neurol Neurosci. 2017;35 (5):547-556. doi:10.3233/RNN-170758

86. Ten Brinke LF, Bolandzadeh N, Nagamatsu LS, et al. Aerobic exercise increases hippocampal volume in older women with probable mild cognitive impairment: a 6-month randomised controlled trial. $\mathrm{Br}$ $J$ Sports Med. 2015;49(4):248-254. doi:10.1136/bjsports-2013093184

87. Pereira ED, Viana CS, Taunay TC, Sales PU, Lima JW, Holanda MA. Improvement of cognitive function after a three-month pulmonary rehabilitation program for COPD patients. Lung. 2011;189 (4):279-285. doi:10.1007/s00408-011-9303-6 


\section{Publish your work in this journal}

Clinical Interventions in Aging is an international, peer-reviewed journal focusing on evidence-based reports on the value or lack thereof of treatments intended to prevent or delay the onset of maladaptive correlates of aging in human beings. This journal is indexed on PubMed Central, MedLine, CAS, Scopus and the Elsevier
Bibliographic databases. The manuscript management system is completely online and includes a very quick and fair peer-review system, which is all easy to use. Visit http://www.dovepress.com/ testimonials.php to read real quotes from published authors. 